\title{
How Readers Perceive and Use a Small Daily Newspaper
}

\author{
For consumers, "local \\ information"-both news and \\ advertising-overwhelms all \\ other considerations.
}

- Maisel has speculated that "the mass media will-contrary to past expectations-play a less important role in the future..."I Mindak, referring to earlier fears that the newspaper was a "dying medium," stated, "History has proved most of these gloomy prognosticators wrong IF (and this is a big if) the media reacted intelligently and quickly to their changing environment. ${ }^{m 2}$

Speculation about the future of the newspaper industry assumed a more ominous overtone in 1975 when a decline in daily newspaper circulation was reported. ${ }^{3}$ The decline in circulation poses a serious question: How well does the newspaper industry understand its changing environment so that it can react "intelligently and quickly" to it?

\section{The Problem}

An essential step toward determining the function of the daily newspaper in today's society will be to determine how consumers perceive the newspaper and how they use it. In an attempt to begin to develop a clearer understanding of consumer perceptions of the daily newspaper, an in-depth study was undertaken

\footnotetext{
'Richard Maisel. "The Decline of Mass Media," Puhlic Opinion Quarterly. 37:159-70. (1973).

2 William A. Mindak, "Do Newspaper Publishers Suffer from Marketing Myopia? Jot RnAl.t5M QiartrRI., 42:43,? 42. (1965).

1-1 otal daily circulation declines $2 \% . "$ Editor \& Puhlisher. April 5. 1975. p. 7 .
}

with a random sample of subscribers to a small daily newspaper in Oklahoma.

The newspaper, in its 74th year of publication, had a total circulation of approximately 4,800 as of Sept. 30,1974 , with 2,300 circulation within the city limits, or $92 \%$ saturation of the city's 2,500 households. The city is a county seat with a population of 6,350 . It is lor cated in a rural area, about 50 miles from a metropolitan area with more than 750,000 population. Although there is no local television station in the city, all three networks and an educational channel are received from the metropolitan area. There is a local radio station and a weekly newspaper is published in the city. In addition, four metropolitan papers in the state have total penetration of $42 \%$ daily and $54 \%$ Sunday in the county in which the newspaper is located.

Aspects of several previous studies were combined in an effort to probe more deeply the question of how consumers actually use the local daily newspaper and their attitudes on the content of the newspaper.

\section{Methodology}

A random sample of subscribers to the newspaper was drawn from the subscription list, with every $\mathbf{n}^{\text {th }}$ home-delivery subscriber within the city limits selected. A team of trained, paid interviewers collected the data in two waves, one week apart.

Since previous studies have indicated

- Dr. Grotta and Dr. Larkin are associate professors in the School of Joumalism at the University of Oklahoma where Miss DePlois is a graduate research assistant. 
that husband and wife in a household do not tend to have similar reading habits, ${ }^{4}$ it was decided that whenever possible, both husband and wife would be interviewed. This was accomplished in 35 households; only one interview was completed in 36 households, for a total of 106 usable interviews from 71 households. The 59 interviews completed in the first wave were compared with the 47 completed in the second wave, and no significant differences were found. Thus, it was assumed that the sample had stabilized adequately. The completed interviews represented nearly $3 \%$ of all households in the city and $2 \%$ of the total population. The profile of the sample was almost identical with the over-all population characteristics reported in the 1970 U.S. Census of the city.

Respondents were not informed that the study involved the local daily newspaper, and the first mention of the newspaper was made in Question 7, when interviewers asked about frequency of reading 34 regular feature items in the newspaper. All data on sources of information had been collected prior to this question.

\section{Results}

Results from all five phases of the study were remarkably consistent. Subscribers said they use the local newspaper for local information-both news and advertising.

Based on previous studies," interest in local content was expected. However, the magnitude of that interest and the great consistency with which it emerged from all phases of the study were surprising.

Where They Get Their Information. Respondents were asked in Question 1: "Where do you get most of your news about: a) national-international events? b) state events? c) local events? d) where to shop?" The question was openended, and respondents could mention as many sources as they wished for each kind of information. Interviewers recorded all mentions of the mass media and also recorded whenever the local daily newspaper was specifically mentioned as a source. Results are summarized in Table 1.

The differences between television and newspapers were striking. For national-international news, $87 \%$ of the respondents cited television and only $31 \%$ mentioned newspapers. Even more revealing was the fact that only $2 \%$ specifically mentioned the local daily newspaper as a source of information on national-international events. Since $57 \%$ of the respondents also subscribed to a metropolitan daily newspaper in the state, it was assumed that the "newspaper" mentioned as a source of national-international news probably was a non-local metropolitan newspaper. The four metropolitan dailies which circulate in the county all carry extensive national and state coverage.

On local news, however, the results were dramatically reversed. Some $80 \%$ cited newspapers as a source of news of local events, and $48 \%$ specifically mentioned the local daily newspaper. Less than $5 \%$ mentioned television as a source of information about local events.

Clearly, subscribers to this small daily newspaper perceive the newspaper as a source of local information, while television dominates as the source of non-local news.

What They Read Most Regularly. In the next phase of the study, respondents were asked whether they read each of 34 regular feature items "nearly every day," "sometimes," or "never." Eight of the items were local, e.g., the editor's personal column, local deaths, local events, etc. The remaining 26 items were non-local, mostly syndicated items, e.g., comic strips, astrology column, crossword puzzle, etc.

For eight local feature items, an average of $57 \%$ responded that they read the items "nearly every day" and $25 \%$

- For example, several unpublished studies conducted by L. Erwin Atwood at Southern Illinois University. Carbondale. 'Several such studies are summarized by Bradley $S$ Greenbers and Michael E. Roloff. "Mass Media Credibility: Research Results and Critical lssues." American Newspaper Publishers Association. News Research Bulletin No. 6. Nov. 4. 1974. 
TABLE 1

Sources of Information by Calegory, in Percent*

Television Radio Newspaper Nenspaper

National-

International

86.8

8.5

31.1

1.9

State

80.2

20.8

42.5

2.8

Local

79.2

48.1

Where to Shop

8.5

64.2

34.0

- Do not total $100 \%$ since respondents could mention more than one source in each catcgory.

said "sometimes," with only $18 \%$ stating that they "never" read the items. The results were reversed for the 26 nonlocal items, with only $21 \%$ responding "nearly every day," $23 \%$ "sometimes," and $56 \%$ "never."

All eight of the local feature items had mean reader-interest scores above the over-all mean for all 34 items, and seven of them were statistically significant. The top six items all were local; five of them were significantly higher than the over-all mean beyond the 0.001 level, with $t$-values ranging from 5.237 to 8.232. Only four of the 26 non-local items were significantly higher than the over-all mean; 14 of them were significantly lower.

Readership Recall in Test Issues. Respondents were asked which items they actually read in the previous day's issue of the local daily newspaper. The procedure was modeled after that used in "The Continuing Study of Newspaper Readership."6 Highest average readership by type of content was for advertising, with $31 \%$, followed closely by local content, with $27 \%$. Syndicated feature items averaged only $16 \%$, state news $15 \%$ and national-international news $13 \%$.

A clear indication of the extent to which readers sought out local information and ignored non-local information (which generally received more prominent display in the newspaper) is shown in this typical example. A national story played on Page 1 with a three-column headline received only $31 \%$ readership.

- The Continuing Study of Nenspaper Reading. Vol. 142. 1955. Advenising Rescarch Bureau (1955).
However, a small, one-column headlined local story buried near the bottom of Page 5 received 36\% readership.

The top three regular feature items in the reader-interest phase of the study emerged as the top three items in the readership recall phase.

What They Would Miss Most, Would Most Like to See Added. In an attempt to determine whether any of the items with low reader-interest or low readership might have great importance to the respondents who do read them, respondents were next asked, "Of all the regular features that appear in the newspaper, which one would you be most disappointed to see taken from the newspaper?" and "Can you think of anything that you would like to see added to the newspaper?" Results were consistent with other phases of the study. Of all items mentioned, $72 \%$ were local in nature, $10 \%$ were syndicated-type items, and $18 \%$ were other items, e.g., "more 'good' news," "more sports," etc.

Advertising Is Local News. The results of this study clearly indicate that . the readers of the small daily newspaper view advertising as a source of local news. It provides them with information on where to shop and also keeps them informed on events and activities of a local nature. This finding was further reinforced by the response to questions concerning the readership of classified advertising. In this study the classified had one of the highest readerships of any type of content with $48 \%$.

In an effort to gain additional informa- 
TABLE 2

Desires for Content Changes, in Percent

\begin{tabular}{|c|c|c|c|}
\hline & More & Sarne & less \\
\hline Local & 62.3 & 37.7 & $0^{*}$ \\
\hline State & 22.6 & 70.8 & 6.6 \\
\hline Advertising & 20.8 & 69.8 & 9.4 \\
\hline Editorials & 17.0 & 77.4 & 5.7 \\
\hline Local Sports ........ & 19.8 & 70.8 & 9.4 \\
\hline Other Sports & 17.0 & 69.8 & 13.3 \\
\hline TV Schedule & 14.2 & 69.8 & 16.0 \\
\hline National & 14.2 & 67.0 & 18.9 \\
\hline 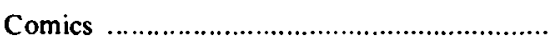 & 4.7 & 67.0 & $28.3+$ \\
\hline
\end{tabular}

- Mean score was significantly higher than over-all mean at $p<0.001$.

+ Mean score was significantly lower than over-all mean at $p<0.001$.

tion on the use of advertising by the readers of this newspaper, the respondents were asked to name the five stores where they did most of their shopping. Fifty-seven different stores were mentioned, but only 17 of these were mentioned by five or more respondents. Of the top 17 stores, the leader was mentioned by $78 \%$ of all respondents, while the second was mentioned by $72 \%$ and the third by $61 \%$. Five stores were mentioned by more than $25 \%$ of all respondents. Although no cause-effect relationship should be inferred, it is noted that of the five stores mentioned most often, all had one or more advertisements that ranked in the top 39 items in readership. No other stores had advertisements that ranked in the top 39 . The five stores most often mentioned were identified as among the advertisers using the greatest amount of advertising space in the newspaper.

Desires for Changes in Content. In the final question, respondents were asked whether they would like to see more, about the same, or less of each of nine categories of content. Results are summarized in Table 2.

Only one category-local content-was significantly higher than the over-all mean for all nine categories. This was significant beyond the 0.001 level, with a t-value of 7.241 .
Reader Desires vs. Content. Although the general rating of the newspaper by respondents was highly favorable $\mathbf{( 9 5 . 3 \%}$ said they would recommend to a new family moving into the city that they subscribe to the local newspaper), the content does not match the respondents' perception of the function of the newspaper.

While the respondents clearly expressed interest in and use of local information, the content of the test issues of the newspaper was predominantly non-local. A comparison of readership and content is presented in Table 3 .

TABLE 3

Readership vs. Content in Test Issues, in Percent

Readership News Hole

Local

27.4

18.1

Syndicated ltems

State

National-

International

\section{Summary and Conclusions}

It is clear that the subscribers to this newspaper perceive their newspaper as a source of local information--both news and advertising. Television and the local newspaper apparently are not perceived 
as competitors, but rather as complementary media; television is the main source of international-national news and entertainment and the local daily newspaper is the source of local information.

The function of a small daily newspaper, as perceived by the subscribers, is to report local information. Television and, to a lesser extent, radio have successfully assumed the role of reporting non-local news to the public much more rapidly than can the local newspaper. Metropolitan newspapers offer detailed information to those readers who wish to pursue issues beyond television and radio coverage. But the local newspaper is the source of local information for persons not living in metropolitan areas.

'Leo Bogart and Frank E. Orenstein, "Mass Medaa and Community Identity in an Interurban Setting." JoI R $\backslash$ Al.M QiARTERLY. 42:179-89, (1965).
This finding tends to support evidence gathered in a number of other studies of the community newspaper. For example, Bogart and Orenstein report in their study that "this study adds to the body of literature which shows that media serve complementary rather than competing functions for the public. The weekly newspaper of the local community is not in competition with the surrounding dailies. It provides a different kind of coverage and focus of interest than the dailies do."

Thus, on the basis of this study, it appears that the relevant product of the local daily newspaper, in terms of the consumer, is local information. This would indicate that publishers of such newspapers should emphasize this aspect of their product and not attempt to compete with television or area metropolitan newspapers on the non-local level.

\section{JOURNALISM QUARTERLY \\ STATEMENT OF OWNERSHIP, MANAGEMENT AND CIRCULATION \\ (Act of August 12, 1970: Section 3685, Title 39, United States Code)}

Date of filing: September 9, 1975

Title of Publication: Joumalism Quarterly

Frequency of issue: Four times a year

Location of known office of publication: 20I Murphy Hall. University of Minnesota. Minneapolis, Minnesota 55455

Location of the headquarters or general business offices of the publication: 201 Murphy Hall, University of Minnesota, Minneapolis, Minnesota 55455

Publisher: Harold W. Wilson, 201 Murphy Hall, University of Minnesota, Minneapolis, Minnesota 55455

Editor: Guido H. Stempel III, School of Journalism, Ohio University, Athens, Ohio 45701

Managing Editor: Randall L. Murray, School of Journalism. Ohio University, Athens, Ohio 45701

Owner: Association for Education in Joumalism, University of Minnesota, Minneapolis, Minnesota

Total number of copies printed

$$
\begin{aligned}
& \text { Average No. copies } \\
& \text { each issue during } \\
& \text { preceding } 12 \text { months }
\end{aligned}
$$
5,000 nearest to filing date

Paid circulation:

Sales through dealers and carriers,

street vendors and counter sales

Mail subscriptions

Total distribution

Office use

Total number of copies distributed

$\begin{array}{rr}0 & 0 \\ 4.620 & 4.835 \\ 4.620 & 4.835 \\ 380 & 365 \\ 5.000 & 5.200\end{array}$

I certify that the statements made by me above are correct and complete.

(Signed) Harold W. Wilson, Business Manager 